\title{
Living alone and cardiovascular health status in residents of a rural village of coastal Ecuador (The Atahualpa Project)
}

\author{
Oscar H. Del Brutto - Daniel Tettamanti • \\ Victor J. Del Brutto • Mauricio Zambrano • \\ Martha Montalván
}

Received: 24 April 2013/Accepted: 13 May 2013/Published online: 4 June 2013

(C) The Japanese Society for Hygiene 2013

\begin{abstract}
Objectives Knowledge of region-specific factors affecting the cardiovascular health $(\mathrm{CVH})$ is mandatory to reduce the growing burden of stroke and ischemic heart disease in rural areas of Latin American. We conducted a population-based case-control study to assess the CVH status of Atahualpa residents-a rural village representative of Coastal Ecuador-according to their living arrangements.

Methods All Atahualpa residents aged $\geq 40$ years and free of stroke or ischemic heart disease that lived alone were identified during a door-to-door census, and their CVH status was compared to that of a sample of residents that lived with relatives. Four controls individually matched for age, gender, education, job and alcohol intake, and randomly selected from different households, were selected for each case-person.

Results A total of 185 persons (37 who lived alone and 148 matched controls) were included. A poor CVH status was found in $89.2 \%$ case-patients and $72.3 \%$ controls $(p=0.03)$. We found significantly worse levels of physical
\end{abstract}

O. H. Del Brutto $(\bowtie) \cdot$ D. Tettamanti · M. Montalván

School of Medicine, Universidad Espíritu Santo-Ecuador,

Guayaquil, Ecuador

e-mail: oscardelbrutto@hotmail.com

O. H. Del Brutto · V. J. Del Brutto · M. Zambrano

Department of Neurological Sciences,

Hospital-Clínica Kennedy, Guayaquil, Ecuador

O. H. Del Brutto

Air Center 3542, PO Box 522970, Miami, Fl 33152-2970, USA

D. Tettamanti

Research Department, Hospital Luis Vernaza,

Guayaquil, Ecuador activity $(p<0.0001)$ and non-significant trends for worse healthy diet and glucose levels among case-persons than controls.

Conclusions This study suggests that social isolation is associated with a worse CVH in rural coastal Ecuador. An ongoing community-based intervention may prove effective to improve $\mathrm{CVH}$ status in these social isolated persons.

Keywords Social isolation - Cardiovascular health . Case-control study $\cdot$ Ecuador $\cdot$ Atahualpa

\section{Introduction}

It has been suggested that loneliness, or absence of social support, is associated with an increased prevalence of cardiovascular risk factors and a higher incidence of vascular outcomes and deaths [1-4]. Most studies addressing this association have been conducted in urban centers of industrialized nations, where living conditions and habits are totally different from those in rural areas of the developing world. The latter are going through a process called "epidemiologic transition", where life expectancy increases and cardiovascular risk factors become more prevalent due to increased life expectancy and changes in the lifestyle of the population [5]. Accurate assessment of cardiovascular risk factors in these regions is mandatory to reduce the burden of stroke and ischemic heart disease, and must be based on local studies evaluating specific risk factors, rather than in the extrapolation of data from studies performed in the developed world. Regional epidemiologic surveys may prove highly cost-effective for developing strategies directed to improve the cardiovascular status of a given population or ethnic group [6]. We performed a cross-sectional, case-control study hypothesizing that 
living arrangements are associated with differences in the cardiovascular health $(\mathrm{CVH})$ status of an adult population of natives/mestizos living in rural coastal Ecuador.

\section{Methods}

The Atahualpa Project (Clinical Trials.gov identifier NCT01627600) is a multi-step, population-based study primarily designed to evaluate the presence of cardiovascular risk factors and to determine the prevalence and incidence of stroke and ischemic heart disease in rural coastal Ecuador. Atahualpa $\left(2^{\circ} 18^{\prime} \mathrm{S}, 80^{\circ} 46^{\prime} \mathrm{W}\right)$ was selected as it is highly representative of the villages of the region. More than $95 \%$ of the population belongs to the Ecuadorian native/mestizo ethnic groups, and their diet is rich in fish and carbohydrates but poor in beef, polyunsaturated fats and dairy products; there are no fast-food restaurants in the village, and most people eat at home. Most men belong to the blue-collar class, and most women are housewives. Inhabitants mobilize within the village mostly by walking or bicycle riding, as few people own a motor vehicle.

The methodology of the Atahualpa Project has been described in detail elsewhere [7]. The IRB of HospitalClínica Kennedy (FWA 00006867) approved the protocol and the informed consent form that had to be signed by persons before entering the study. Then, trained field personnel performed a door-to-door survey to detect all Atahualpa residents and to apply questionnaires designed to evaluate the CVH status of people aged $\geq 40$ years who were free of stroke and ischemic heart disease [8]. We used CVH metrics proposed by the American Heart Association (Table 1). All these persons were also screened for the presence of stroke and ischemic heart disease in a threephase survey [9]. DuringPhase I, suspected cases were detected by rural doctors with the use of validated field questionnaires [10, 11]. In Phase II, certified neurologists and cardiologists moved to Atahualpa to evaluate persons who screened as suspected cases, as well as two randomly selected negative individuals matched by age and gender for each positive case; such evaluation also included a 12-lead ECG performed in the field. Neurologists and cardiologists were blinded as to whether persons were suspected positive cases or negative individuals. Stroke was diagnosed in patients who had experienced a rapidly developing event characterized by clinical signs of focal or global disturbance of cerebral function, lasting more than $24 \mathrm{~h}$, with no apparent cause other than vascular, and ischemic heart disease was diagnosed by clinical judgment and ECG findings. In Phase III, patients with a confirmed stroke and ischemic heart disease were invited to undergo further examination, including brain MRI, MRA of
Table 1 Cardiovascular health metrics and status according to the American Heart Association

Cardiovascular health metrics

1. Smoking: ideal (never or quit $>1$ year), intermediate (quit $\leq 1$ year) and poor (current smoker).

2. Body mass index: ideal $\left(<25 \mathrm{~kg} / \mathrm{m}^{2}\right)$, intermediate ( 25 to $\left.<30 \mathrm{~kg} / \mathrm{m}^{2}\right)$ and poor $\left(\geq 30 \mathrm{~kg} / \mathrm{m}^{2}\right)$.

3. Physical activity: ideal $(\geq 150 \mathrm{~min} /$ week moderate intensity or $\geq 75 \mathrm{~min} /$ week vigorous intensity or equivalent combination), intermediate (1-149 $\mathrm{min} /$ week moderate intensity or 1-74 min/week vigorous intensity or equivalent combination) and poor (no moderate and vigorous activity).

4. Diet: ideal (4-5 healthy components), intermediate (2-3 healthy components) and poor (0-1 healthy component); based on 5 health dietary components ( $\geq 4.5$ cups fruits and vegetables/day, $\geq$ two $3.5-\mathrm{oz}$ servings fish/week, $\geq$ three $1-\mathrm{oz}$ equivalent servings fiber-rich whole grains/day, $<1,500 \mathrm{mg}$ sodium/day, and $\leq 450 \mathrm{kcal}$ sugar-sweetened beverages/week).

5. Total cholesterol: ideal (untreated and $<200 \mathrm{mg} / \mathrm{dL}$ ), intermediate (treated to $<200 \mathrm{mg} / \mathrm{dL}$ or $200-239 \mathrm{mg} / \mathrm{dL}$ ) and poor $(\geq 240 \mathrm{mg} / \mathrm{dL})$.

6. Blood pressure: ideal (untreated and $<120 /<80 \mathrm{mmHg}$ ), intermediate (treated to $<120 /<80 \mathrm{mmHg}$ or $120-139 /$ $80-89 \mathrm{mmHg})$ and poor $(\geq 140 / 90 \mathrm{mmHg})$.

7. Fasting glucose: ideal (untreated and $<100 \mathrm{mg} / \mathrm{dL}$ ), intermediate (treated to $<100 \mathrm{mg} / \mathrm{dL}$ or $100-125 / \mathrm{mg} / \mathrm{dL}$ ) and poor $(\geq 126 \mathrm{mg} / \mathrm{dL})$.

Cardiovascular health status

1. Ideal CVH status: All seven CVH metrics in the ideal range.

2. Intermediate $\mathrm{CVH}$ status: At least one $\mathrm{CVH}$ metric in the intermediate range, but no poor metrics.

3. Poor CVH status: At least one $\mathrm{CVH}$ metric in the poor range.

intracranial vessels, transthoracic echocardiogram, Doppler examination of extracranial arteries, and a treadmill test.

The initial census yielded 2478 residents, of whom 642 were aged $\geq 40$ years. Of these, 26 were excluded for a diagnosis of stroke or ischemic heart disease. In a total of 616 stroke- and ischemic heart disease-free individuals, 37 (6\%) lived alone and the remaining 579 lived with their spouses, siblings or other relatives. Persons who lived alone were older (mean age, $65.6 \pm 13.1$ vs $58.3 \pm 12.3$ years) and were more often men (46.0 vs $40.2 \%$ ) than those who lived with relatives.

For the purposes of the present study, persons were classified according to their living arrangements, and those who lived alone were selected as case-persons. Four controls individually matched for age, gender, education, job, and alcohol intake were selected for each case-person among the 579 individuals who lived with relatives. The controls were randomly selected from 148 different households to reduce the risk of unmeasured confounders. $\mathrm{CVH}$ metrics and status were compared across case-persons and controls. All the 37 case-persons had been living alone for at least 1 year before the census. 
Table 2 Characteristics of case-persons and controls included in this study

* Persons free of stroke and ischemic heart disease

$\dagger$ Persons living alone

† Persons living with relatives, matched to persons living alone for age, gender, education, job, and alcohol intake

\begin{tabular}{lllll}
\hline & $\begin{array}{l}\text { Atahualpa residents } \\
\geq 40 \text { years } \\
(n=616)^{*}\end{array}$ & $\begin{array}{l}\text { Case- } \\
\text { persons } \dagger \\
(n=37)\end{array}$ & $\begin{array}{l}\text { Controls } \$ \\
(n=148)\end{array}$ & $p$ value \\
\hline Age (mean \pm SD) & $58.7 \pm 12.5$ & $65.6 \pm 13.1$ & $65.1 \pm 12.5$ & Matched \\
Men, \% & 40.6 & 45.9 & 45.9 & Matched \\
Up to primary school education, \% & 64.4 & 56.8 & 58.8 & Matched \\
Retired, \% & 15.3 & 29.7 & 25 & Matched \\
Alcohol intake $>50$ g/day, $\%$ & 14.1 & 8.1 & 6.1 & Matched \\
Poor CVH status, \% & 70 & 89.2 & 72.3 & 0.03 \\
Poor CVH metrics per person & $1.2 \pm 1$ & $1.5 \pm 0.9$ & $1.2 \pm 1$ & 0.04 \\
$\quad$ mean \pm SD) & 1.8 & & & \\
Current smoker, \% & 26 & 2.8 & 0 & - \\
BMI $\geq 30 \mathrm{~kg} / \mathrm{m}{ }^{2}, \%$ & 5.8 & 27.6 & 19.6 & 0.783 \\
Poor physical activity, \% & 2.8 & 13.5 & 6.1 & 0.0001 \\
Poor diet, $\%$ & 8.6 & 8.1 & 2 & 0.06 \\
Total cholesterol $\geq 240 \mathrm{mg} / \mathrm{dL}, \%$ & 37.8 & 5.4 & 9.5 & 0.433 \\
Blood pressure $\geq 140 / 90 \mathrm{mmHg}, \%$ & 31.7 & 51.4 & 43.9 & 0.427 \\
Fasting glucose $\geq 126 \mathrm{mg} / \mathrm{dL}, \%$ & 48.6 & 33.2 & 0.08 \\
\hline
\end{tabular}

$p=0.06)$ and poor fasting glucose levels (48.6 vs $33.2 \%$, $p=0.08)$ among case-persons and controls.

Descriptive statistics were presented as means with standard deviations for continuous variables and as percentages for categorical variables. Statistical analysis of data was carried out using SPSS18 (SPSS Inc., Chicago, IL, USA). Statistical significance was tested by the use of the $\chi^{2}$ test or the Fisher's exact for categorical variables, and by te Kruskal-Wallis test for continuous variables. All $p$ values were two-sided and a $p$ value of $<0.05$ was considered statistically significant.

\section{Results}

The study evaluated 37 case-persons and 148 matched controls (Table 2). The former represented all Atahualpa residents free of stroke or ischemic heart disease who lived alone, and the controls represented the $25.6 \%$ of a total of 579 persons who had been living with relatives during the year before the census. As case-persons and controls were properly matched, there were no differences in sociodemographic parameters across the two groups. There was a marginally significant increase in the odds for having a poor CVH status between case-persons and controls (OR: $3.16,95 \%$ CI 1.05-9.48; $p=0.03$ ) as well as in the mean number of $\mathrm{CVH}$ metrics in the poor range per person between case-persons and controls $(1.5 \pm 0.9$ vs $1.2 \pm 1$, $p=0.04)$. With the exception of a poor level of physical activity, which was more common among case-persons than controls ( 13.5 vs $6.1 \%, p<0.0001)$, there were no significant differences in the percentage of persons with the other six $\mathrm{CVH}$ metrics in the poor range among case-persons and controls. It must be noted, however, the finding of non-significant trends for poor healthy diet ( 8.1 vs $2 \%$,

\section{Discussion}

As recently stressed, few concepts in epidemiology have been more difficult to define than the measurement of loneliness [4]. Indeed, it has been noted that loneliness does not necessarily means "living alone", but the feelings and perceptions of a given individual on the lack of social support in times of stress, illness, or particular needs [12]. While some investigators have used the concept of "living alone" as a proxy for absence of social support [1], other have chosen the concept of "social isolation", that is, lack of friendship networks [2]. For this study, we chose the former since in rural communities it is most likely that the family — and not friends - take care for the particular needs of a given person. Irrespective of these considerations, it is likely that the real or perceived absence of social support contacts induces depression and reduces the person's options for an adequate nutrition, proper mobility, and medication compliance; all these factors have been associated with worse health outcomes [13].

In this study, we found a modest adverse effect of living alone on the $\mathrm{CVH}$ status and on some $\mathrm{CVH}$ metrics (physical activity, health diet, and glucose levels), which is understandable in the light of the living habits of this subset of persons and the lack of family support. We did not find differences in blood pressure control or in other $\mathrm{CVH}$ metrics. This could be related to the small number of casepersons, a fact that may represent a potential weakness of this study. The major strength of this analysis, however, is 
that it is based on a community cohort, including all persons who lived alone in the village and a representative sample $(25 \%)$ of people who live with relatives.

Another potentially perceived limitation of this study is that we did not investigate the presence of comorbid mental disorders that may be associated with a poor CVH status across case-persons and controls. It is possible that persons lived alone as they have lost their abilities to be social engaged, or they have been isolated due to social stigma, which is rather common in the rural areas of developing countries [14]. However, we also matched our cases and controls by job, so the percentage of unoccupied persons (which could be associated with mental illness) was similar across both groups (29.7 vs $25 \%$, $p=0.557)$.

In conclusion, results from the present survey are in accord with those reported in other studies and reinforce the concept that social isolation may be detrimental to human health, not only in urban centers but also at the rural level. What is not known, however, is whether a specific intervention could be of particular value in this subset of persons. During the study years of the Atahualpa Project, we will apply an intervention program called "know your numbers", by which people who voluntarily seek our Community Center will be instructed on how to improve their CVH status and will be periodically visited at their homes to track on their efforts on reducing risk factors [15]. By the end of the study, it will be possible to evaluate whether such simple intervention benefited mostly those persons living alone than those living with relatives as, according to our aim, the former will feel the support of people interested in their health status.

Acknowledgments This study was partially supported by an unrestricted grant from Universidad Espíritu Santo-Ecuador, GuayaquilEcuador.

Conflict of interest The authors declare that they have no conflicts of interest.

\section{References}

1. Udell JA, Steg PG, Scirica BM, Smith SC Jr, Ohman EM, Eagle $\mathrm{KA}$, et al. Living alone and cardiovascular risk in outpatients at risk of or with atherothrombosis. Arch Intern Med. 2012;172: 1086-95.

2. Rodriguez CJ, Elkind MSV, Clemow L, Jin Z, Di Tulio M, Sacco $\mathrm{RL}$, et al. Association between social isolation and left ventricular mass. Am J Med. 2011;124:164-70.

3. Rozanski A, Blumenthal JA, Davidson KW, Saab PG, Kubzansky L. The epidemiology, pathophysiology, and management of psychosocial risk factors in cardiac practice: the emerging field of behavioral cardiology. J Am Coll Cardiol. 2005;45:637-51.

4. Bucholz EM, Krumholz HM. Loneliness and living alone. What are we really measuring. Arch Intern Med. 2012;172:1084-5.

5. Omran AR. The epidemiologic transition: a theory of the epidemiology of population change. 1971. Milbank Q. 2005;83:731-57.

6. Del Brutto OH, Dong C, Rundek T, Elkind MSV, Del Brutto VJ, Sacco RL. Cardiovascular health status among Caribbean Hispanics living in Northern Manhattan and Ecuadorian natives/ mestizos in rural coastal Ecuador: a comparative study. J Commun Health. 2013. doi:10.1007/s10900-013-9658-0.

7. Del Brutto OH, Peñaherrera E, Ochoa E, Santamaría M, Zambrano M, Del Brutto VJ. Door-to-door survey of cardiovascular health, stroke and ischemic heart disease in rural coastal Ecuador-The Atahualpa Project. Methodology and operational definitions. Int J Stroke. 2013. doi:10.1111/ijs.12030.

8. Del Brutto OH, Santamaría M, Ochoa E, Peñaherrera E, Santibáñez R, Pow-Chon-Long $F$, et al. Population-based study of cardiovascular Health in Atahualpa, a rural village of coastal Ecuador. Int J Cardiol .2013. http://dx.doi.org/10.1016/j.ijcard. 2013.01.017.

9. Del Brutto OH, Santamaría M, Zambrano M, et al. Stroke in rural coastal Ecuador: a community-based survey. Int J Stroke. 2013. doi:10.1111/ijs.12102.

10. Del Brutto OH, Idrovo L, Mosquera A, et al. Validación de un cuestionario para detección de ictus en poblaciones hispanoparlantes. Rev Neurol. 2004;39:301-4.

11. Cosín J, Asín E, Marrugat J, et al. Prevalence of angina pectoris in Spain. Eur J Epidemiol. 1999;15:323-30.

12. Sherbourne CD, Stewart AL. The MOS social support survey. Soc Sci Med. 1991;32:705-14.

13. Perissimotto CM, Cenzer IS, Covinsky KE. Loneliness in older persons. A predictor of functional decline and death. Arch Intern Med. 2012;172:1078-83.

14. Audu IA, Idris SH, Olisah VO, Sheikh TL. Stigmatization of people with mental illness among inhabitants of a rural community in northern Nigeria. Int J Social Psychiatry. 2013;59: $55-60$.

15. Del Brutto $\mathrm{OH}$, Montalván $\mathrm{M}$, Tettamanti $\mathrm{D}$, Peñaherrera $\mathrm{E}$, Santibáñez R, Pow-Chon-Long F, et al. The "know your numbers" program in Atahualpa-A pilot aimed to reduce cardiovascular diseases and stroke. Int J Cardiol 2013. http://dx.doi.org/ 10.1016/j.ijcard.2013.04.049. 